\title{
Direct Observation of an Isolated Cyclic Sodium Poly(styrenesulfonate) Molecule by Atomic Force Microscopy
}

\author{
Daisuke Kawaguchi, Takashi Nishu, Atsushi Takano, and Yushu Matsushita ${ }^{\dagger}$ \\ Department of Applied Chemistry, Graduate School of Engineering, Nagoya University, \\ Furo-cho, Chikusa-ku, Nagoya 464-8603, Japan
}

(Received November 13, 2006; Accepted December 16, 2006; Published February 2, 2007)

KEY WORDS Cyclic Polymer / Single-Molecule / Atomic Force Microscopy (AFM) /

Polyelectrolyte /

[doi:10.1295/polymj.PJ2006155]

Cyclic polymers bearing no chain ends are attractive since these may lead to significant changes in the properties such as chain dimensions, ${ }^{1-7}$ glass transition temperatures, ${ }^{8-11}$ viscoelasticity, ${ }^{11-13}$ diffusion $^{14-16}$ and phase-separated structures of cyclic diblock copolymers ${ }^{17}$ in comparison with corresponding linear counterparts due to their topological constraints. Many efforts have been devoted to synthesize and characterize cyclic polymers so far. ${ }^{3,18-29}$ The basic strategies preparing cyclic polymers are end-to-end ring closure reactions: coupling reaction between living polymers with functional groups on both ends and bifunctional linking agents $s^{3,18,21,23,25}$ or intramolecular coupling reaction between chain ends of telechelic macromonomers. ${ }^{26}$ It should be noted that cyclization products include undesired linear precursors, and dimmer and/or catanated polymers for both preparing methods. Hence, the products should be fractionated by using fractional precipitation, gel permeation chromatography (GPC) and/or ultracentifugation sedimentation, making use of the fact that chain dimension of cyclic polymers in solution is smaller than that of linear counterpart at the same molecular weight. ${ }^{1,30,31}$ However, since lower molecular weight components in linear precursors inevitably tend to be collected in fractionation process, the determination of purity is very important to characterize cyclic polymers.

There are no direct methods to prove a cyclic structure of molecules with high molecular weight, whereas such fractionation techniques as GPC and ultracentifugation sedimentation have been used as indirect characterization methods. It is well-recognized that conventional NMR is useful to pursue chemical structure of junction point produced by cyclization reaction occurred and that matrix-assisted laser desorption/ ionization mass spectrometry (MALDI-MASS) was also applicable to analyze cyclic structures. ${ }^{21,23}$ However, these methods are limited to a relatively low molecular weight polymer $(<10 \mathrm{k})$. Recently, liquid chromatography at the critical condition (LCCC) based on a combination of entropic and enthalpic separations has been also applied to separate a cyclic polymer from cyclic/linear mixture. ${ }^{32,33}$ Since the peaks for these two components can be clearly split, this method makes it possible to estimate the purity of the cyclic polymers. ${ }^{33}$ However, all the works mentioned above give us indirect information, in other words, there is no explicit evidence for cyclic structure of the chain.

Scanning probe microscopy (SPM) has the capability to observe a single synthetic macromolecule as well as a large DNA molecule. ${ }^{34-36}$ In order to visualize a single polymer chain, it is necessary to deposit an isolated molecule on substrate and to expand the polymer chain. To do so, a polyelectrolyte molecule is suitable for this study because it should be expanded by an intramolecular charge repulsion. In this study, we prepare cyclic sodium poly(styrenesulfonate) from cyclic polystyrene by sulfonation reaction, and we visually confirm the closed loop structure of the isolated cyclic polyelectrolyte by SPM.

\section{EXPERIMENTAL}

Linear polystyrene, 1-PS, was prepared by a living anionic polymerization using naphthalene potassium as an initiator. Weight-averaged molecular weight, $M_{\mathrm{w}}$, of 1-PS, determined by multi-angle laser light scattering (MALLS), is $115 \mathrm{k}$. A part of 1-PS was used for cyclization reaction. The details of the synthesis and characterization of cyclic polystyrene, c-PS, were

${ }^{\dagger}$ To whom correspondence should be addressed (Tel: +81-52-789-4604, Fax: +81-52-789-3210, E-mail: yushu@ apchem.nagoya-u.ac.jp). 


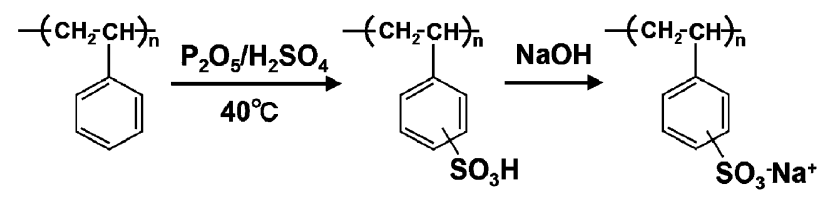

Scheme 1. Sulfonation of polystyrene by Vink's method.
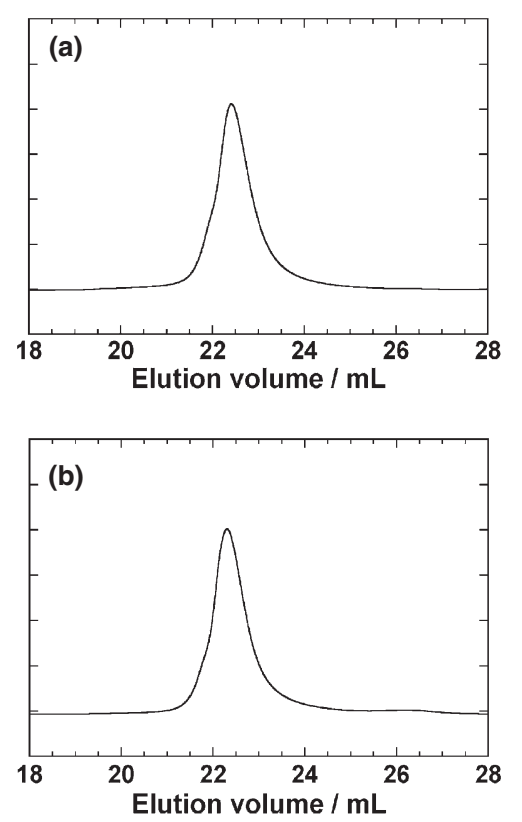

Figure 1. Gel permeation chromatograms of (a) cyclic sodium poly(styrenesulfonate) (c-PSS) and (b) linear one (1-PSS).

described elsewhere. ${ }^{33}$ Molecular weight distribution, $M_{\mathrm{w}} / M_{\mathrm{n}}$, of c-PS and 1-PS evaluated by gel permeation chromatography (GPC) were 1.02 and 1.04 , respectively, and the purity of c-PS evaluated by LCCC measurement was $95 \%$. Both c-PS and 1-PS were sulfonated by Vink's method, followed by neutralization by treating with sodium hydroxide as shown in Scheme $1 .{ }^{37}$ Figure 1 shows a gel permeation chromatograms of (a) cyclic sodium poly(styrenesulfonate), c-PSS, and (b) linear one, 1-PSS, using $0.1 \mathrm{M}$ sodiumperchlorate acetonitrile $/ \mathrm{H}_{2} \mathrm{O}$ solution $(0.225 / 0.775$, $\mathrm{vol} / \mathrm{vol}$ ) as an eluent.

It is apparent that both GPC chromatograms exhibit a single peak at the peak top around $22 \mathrm{~mL}$ and shows no peak tailing. Hence, successful sulfonation reaction and no chain-scission were confirmed by GPC. Degrees of sulfonation of c-PSS and 1-PSS determined by inductively coupled plasma (ICP) mass spectroscopy were $74 \%$ and $72 \%$, respectively. For a comparison, l-PSS with $M_{\mathrm{w}}$ of $1.55 \times 10^{6}$, abbreviated as 1-PSS-long, was also used. ${ }^{38} M_{\mathrm{w}}$ for the 1-PSS-long was evaluated by light scattering. Since this polymer was synthesized by a radical polymerization from styrenesulfonate monomers and was fractionated by a thermodynamic method, its degree of sulfonation is $100 \%$.

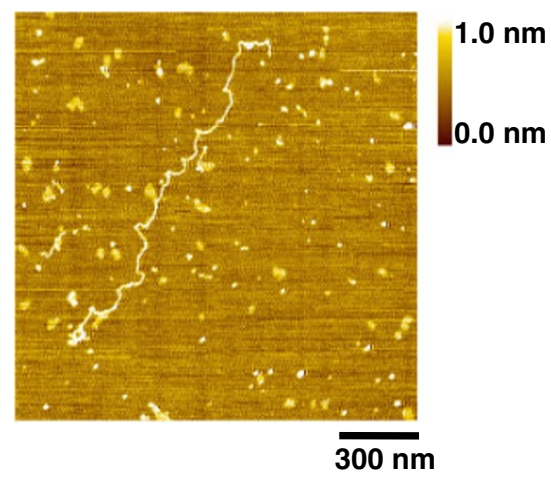

Figure 2. An AFM image of linear sodium poly(styrenesulfonate) with $M_{\mathrm{w}}$ of $1.55 \times 10^{6}$.

c-PSS, 1-PSS and 1-PSS-long were dissolved into deionized water and their concentrations were set to be $c a .4 \mathrm{mg} / \mathrm{L}$. These solutions of $0.4 \mathrm{~mL}$ were dropped onto mica and successively most of solutions were blown out by nitrogen gas stream, consequently a few PSS molecules were adsorbed on the mica substrate. The PSS molecules were observed by atomic force microscopy (AFM) with intermittent contact mode. AFM images were obtained by an SPA $300 \mathrm{HV}$ with an SPI3800 controller (Seiko Instruments Industry Co., Ltd.) at $293 \mathrm{~K}$ in air. A cantilever tip used for this observation was microfabricated from silicon, and its spring constant and resonant frequency were $33 \mathrm{~N} \mathrm{~m}^{-1}$ and $324 \mathrm{kHz}$, respectively.

\section{RESULTS AND DISCUSSION}

To confirm the possibility of visualizing an isolated polyelectrolyte by AFM, firstly we tried to observe 1-PSS-long. Figure 2 shows an AFM image of the isolated 1-PSS with $M_{\mathrm{w}}$ of $1.55 \times 10^{6}$ on a mica substrate. It is obvious that a long linear polymeric chain is observed. The contour length of the chain traced from Figure 2 was $1.82 \mu \mathrm{m}$ and the value is in good agreement with the calculated value of $1.89 \mu \mathrm{m}$, evaluated from its degree of polymerization and $\mathrm{C}-\mathrm{C}-\mathrm{C}$ bond length for the repeating unit, i.e., $0.25 \mathrm{~nm}$. From the same image, the height and width of the molecule were determined to be $0.3-0.5 \mathrm{~nm}$ and $10-20 \mathrm{~nm}$, respectively. The height well corresponds to the diameter of the molecule, while the apparent width is much larger than the actual size due to convolution of the AFM tip. Additionally one notices that the chain was elongated along one direction and fairly anisotropic probably owing to the effect of gas blowing during sample preparation. This result clearly indicates that an individual 1-PSS-long chain on a mica substrate can be verified by AFM observation, where PSS is electrically neutral since $\mathrm{Na}^{+}$and $\mathrm{SO}_{3}{ }^{-}$are canceled out each other. We believe that 1-PSS-long 
(a)

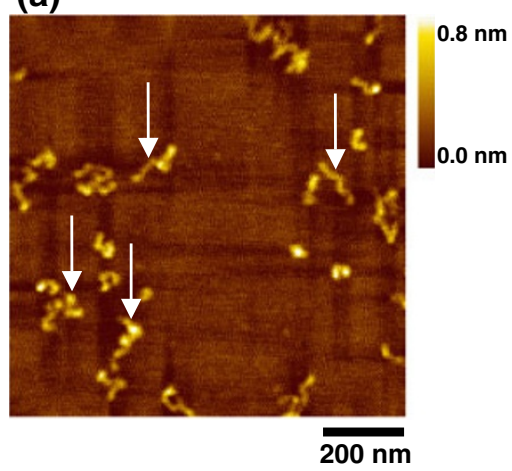

(b)

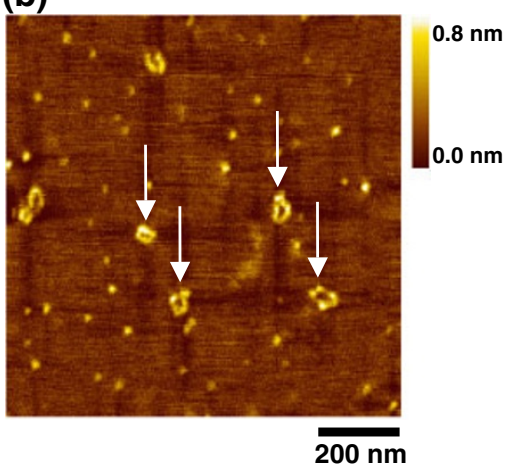

(c)

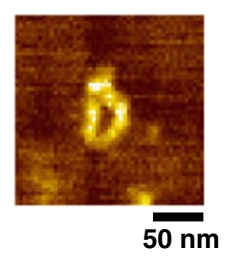

(d)

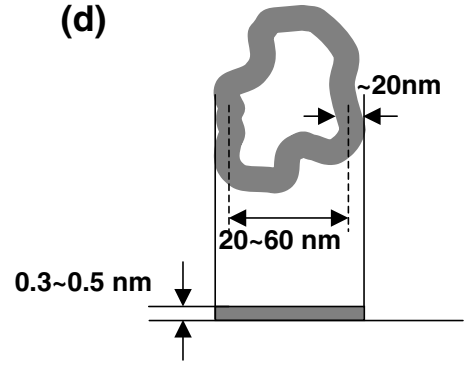

Figure 3. AFM images of (a) l-PSS and (b) c-PSS on mica substrate, in which arrows indicate isolated macromolecules, and (c) an enlarged image of (b). (d) A schematic representation of a cyclic molecule on a two dimensional plane.

is attached to mica surface through the adsorbed water layer formed on mica. Furthermore, many small dots observed in Figure 2 might be some small dust adsorbed on the substrate during the drying process of the sample.

Figure 3 shows AFM images of isolated 1-PSS and c-PSS molecules. The linear molecules whose apparent contour lengths range from 150 to $250 \mathrm{~nm}$ can be recognized in Figure 3(a) for 1-PSS. In contrast, all the molecules represent ring-shaped structures for c-PSS as shown in Figure 3(b), so that the purity of the cyclic polymers is sufficiently high. The enlarged image and schematic representation of c-PSS are shown in Figure 3(c) and (d), respectively. The apparent contour lengths measured for c-PSS molecules range between 160 and $210 \mathrm{~nm}$, whereas the length of a fully stretched PSS chain with the corresponding degree of polymerization is calculated to be $270 \mathrm{~nm}$. Hence, the observed lengths for both 1-PSS and c-PSS molecules are apparently shorter than the expected one and the apparent length distribution for molecules is broad. The reasons for these two results are discussed as follows.

$M_{\mathrm{w}} / M_{\mathrm{n}}$ s for the c-PS and 1-PS before sulfonation reaction are narrow, and no chain-scission after sulfonation reaction is confirmed by GPC. Thus, it is likely that $M_{\mathrm{w}} / M_{\mathrm{n}}$ s for the c-PSS and 1-PSS are nearly equivalent to that for c-PS and 1-PS. For this reason, it can be assumed that the effect of molecular weight distribution on contour length distribution for PSS molecules is negligibly small.

One possible reason for the difference between the expected length and the observed one is the incomplete sulfonation of c-PSS, namely it leads detachment of unsulfonated portion in the c-PSS from the substrate, resulting in the reduction of the projected contour length. There may be several small kinks of chains perpendicular to the substrate, which were all ignored owing to a limited resolution. ${ }^{34}$

The issue of the incomplete sulfonation of PSS molecules is not irrelevant to the apparent contour length distribution for both 1-PSS and c-PSS molecules. Degrees of sulfonation for c-PSS and 1-PSS are $72 \%$ and $74 \%$, it allows certain amount of distribution among molecules. It can be speculated that the number of the kinks in a chain increases with decreasing the degree of sulfonation based on above discussion. Hence, it would be expected that the distribution of the apparent contour length for PSS molecules is closely related to the distribution of the degree of sulfonation.

In conclusion, 1-PSS and c-PSS was prepared by a living anionic polymerization and a subsequent sulfonation reaction, and isolated 1-PSS and c-PSS molecules on mica were directly observed by AFM. The molecule was adsorbed on a mica substrate two dimensionally, and the contour length of the molecule was reasonably in good agreement with the calculated one from its molecular structure. In summary, the ring-shaped structure of a synthetic cyclic polymer 
was evidently confirmed based on the direct observation of the individual chains by AFM, and the results obtained in the present work greatly contribute to the study on cyclic polymers.

Acknowledgment. We gratefully thank to Dr. Matsuura and Prof. Umemura at Department of Applied Chemistry in Nagoya University for their help taking ICP mass analysis.

\section{REFERENCES}

1. B. H. Zimm and W. H. Stockmayer, J. Chem. Phys., 17, 1301 (1949).

2. a) J. S. Higgins, K. Dodgson, and J. A. Semlyen, Polymer, 20, 553 (1979).

b) C. J. C. Edwards, R. W. Richards, R. F. T. Stepto, K. Dodgson, J. S. Higgins, and J. A. Semlyen, Polymer, 25, 365 (1984).

3. a) J. Roovers and P. M. Toporowski, Macromolecules, 16, 843 (1983).

b) J. Roovers, J. Polym. Sci., Polym. Phys. Ed., 23, 1117 (1985).

4. M. E. Cates and J. M. Deutsch, J. Phys. (Paris), 47, 2121 (1986).

5. M. Müller, J. P. Wittmer, and M. E. Cates, Phys. Rev. E: Stat., Nonlinear, Soft Matter Phys., 53, 5063 (1996).

6. a) S. Brown and G. Szamel, J. Chem. Phys., 108, 4705 (1998).

b) S. Brown and G. Szamel, J. Chem. Phys., 109, 6184 (1998).

7. V. Arrighi, S. Gagiliardi, A. C. Dagger, J. A. Semlyen, J. A. Higgins, and M. J. Shenton, Macromolecules, 37, 8057 (2004).

8. E. A. Di Marzio and C. M. Guttman, Macromolecules, 20, 1403 (1987).

9. X. Liu, D. Chen, Z. He, H. Zhang, and H. Hu, Polym. Commun., 32, 123 (1991).

10. a) Y. Gan, D. Dong, and T. E. Hogen-Esch, Macromolecules, 28, 383 (1995).

b) G. G. Nossarev and T. E. Hogen-Esch, Macromolecules, 35, 1604 (2002).

11. P. G. Santangelo, C. M. Roland, T. Chang, D. Cho, and J. Roovers, Macromolecules 34, 9002 (2001).

12. G. B. McKenna, B. J. Hostetter, N. Hadjichristidis, L. J. Fetters, and D. J. Plazek, Macromolecules, 22, 1834 (1989).

13. a) A. Takano, I. Kamaya, Y. Takahashi, and Y. Matsushita, Macromolecules, 38, 9718 (2005).

b) Y. Takahashi, Y. H. Song, N. Nemoto, A. Takano, Y. Akazawa, and Y. Matsushita, Macromolecules, 38, 9724 (2005).

14. D. Kawaguchi, K. Masuoka, A. Takano, K. Tanaka, T. Nagamura, N. Torikai, R. M. Dalgliesh, S. Langridge, and Y. Matsushita, Macromolecules, 39, 5180 (2006).

15. a) P. J. Mills, J. W. Mayer, E. J. Kramer, G. Hadziioannou, P. Lutz, C. Strazielle, P. Rempp, and A. J. Kovacs, Macromolecules, 20, 513 (1987).

b) S. F. Tead, E. J. Kramer, G. Hadziioannou, M. Antonietti,
H. Sillescu, P. Lutz, and C. Strazielle, Macromolecules, 25, 3942 (1992).

16. T. Cosgrove, P. C. Griffiths, J. Hollingshurst, R. D. C. Richards, and J. A. Semlyen, Macromolecules, 25, 6761 (1992).

17. a) Y. Matsushita, H. Iwata, T. Asari, T. Uchida, G. ten Brinke, and A. Takano, J. Chem. Phys., 121, 1129 (2004). b) A. Takano, O. Kadoi, K. Hirahara, S. Kawahara, Y. Isono, J. Suzuki, and Y. Matsushita, Macromolecules, 36, 3045 (2003).

18. D. Geiser and H. Höcker, Macromolecules, 13, 653 (1980).

19. G. Hild, A. Kohler, and P. Rempp, Eur. Polym. J., 16, 525 (1980).

20. a) B. Vollmert and J. X. Huang, Makromol. Chem. Rapid Commun., 1, 333 (1980).

b) B. Vollmert and J. X. Huang, Makromol. Chem. Rapid Commun., 2, 467 (1981).

21. a) L. Rique-Lurbet, M. Schappacher, and A. Deffieux, Macromolecules, 27, 6318 (1994).

b) H. Pasch, A. Deffieux, R. Ghahary, M. Schapacher, and L. Rique-Lurbet, Macromolecules, 30, 98 (1997).

22. a) H. Oike, S. Kobayashi, T. Mouri, and Y. Tezuka, Macromolecules, 34, 2742 (2001).

b) H. Oike, T. Mouri, and Y. Tezuka, Macromolecules, $\mathbf{3 4}$, 6229 (2001).

23. H. Ohtani, H. Kotsuji, H. Momose, Y. Matsushita, I. Noda, and S. Tsuge, Macromolecules, 32, 6541 (1999).

24. a) K. Dodgson and J. A. Semlyen, Polymer, 18, 1265 (1977). b) A. C. Dagger and J. A. Semlyen, Polymer, 39, 2621 (1998).

c) A. C. Dagger and J. A. Semlyen, Polymer, 40, 3243 (1999).

25. a) Y. Gan, D. H. Dong, S. Carlotti, and T. E. Hogen-Esch, J. Am. Chem. Soc., 122, 2130 (2000).

b) K. A. Alberty, E. Tillman, S. Carlotti, K. King, S. E. Bradforth, T. E. Hogen-Esch, D. Parker, and W. J. Feast, Macromolecules, 35, 3856 (2002).

26. a) A. Takano, A. Nonaka, O. Kadoi, K. Hirahara, S. Kawahara, Y. Isono, N. Torikai, and Y. Matsushita, $J$. Polym. Sci., Part B: Polym. Phys., 40, 1582 (2002).

b) A. Takano, Y. Kushida, K. Aoki, K. Masuoka, K. Hayashida, D. Cho, D. Kawaguchi, and Y. Matsushita, Macromolecules, in press.

27. C. W. Bielawski, D. Benitez, and R. H. Grubbs, Science, 297, 2041 (2002).

28. a) B. M. White, W. P. Watson, E. E. Barthelme, and H. W. Beckham, Macromolecules, 35, 5345 (2002).

b) S. Singla, T. Zhao, and H. W. Beckham, Macromolecules, 36, 6945 (2003).

29. K. Adachi, H. Takasugi, and Y. Tezuka, Macromolecules, 39, 5585 (2006).

30. E. F. Casassa, J. Polym. Sci., Part A, 3, 605 (1965).

31. M. Fukatsu and M. Kurata, J. Chem. Phys., 44, 315 (1966).

32. a) H. C. Lee, H. Lee, W. Lee, T. Chang, and J. Roovers, Macromolecules, 33, 8119 (2000).

b) D. Cho, S. Park, K. Kwon, T. Chang, and J. Roovers, Macromolecules, 34, 7570 (2001).

c) W. Lee, H. Lee, H. C. Lee, D. Cho, T. Chang, A. A. Gorbunov, and J. Roovers, Macromolecules, 35, 529 (2002). 
33. D. Cho, K. Masuoka, K. Koguchi, T. Asari, D. Kawaguchi, A. Takano, and Y. Matsushita, Polym. J., 37, 506 (2005).

34. a) J. Kumaki, Y. Nishikawa, and T. Hashimoto, J. Am. Chem. Soc., 118, 3321 (1996).

b) J. Kumaki and T. Hashimoto, J. Am. Chem. Soc., 125, 4907 (2003).

35. T. Kawauchi, J. Kumaki, and E. Yashima, J. Am. Chem.
Soc., 127, 9950 (2005).

36. H. Aoki, M. Anryu, and S. Ito, Polymer, 46, 5896 (2005).

37. H. Vink, Macromol. Chem., 182, 279 (1981).

38. a) M. Nagasawa and Y. Eguchi, J. Phys. Chem., 71, 880 (1967).

b) A. Takahashi, T. Kato, and M. Nagasawa, J. Phys. Chem., 71, 2001 (1967). 